\title{
Potencial de mucilagem do cacto xique-xique como tratamento superficial para blocos de terra comprimida
}

\author{
Potential of cactos xique-xique mucilage as a surface \\ treatment for compressed earth blocks
}

\section{Ana Beatriz Egypto Queiroga da Nóbrega Aluísio Braz de Melo}

\section{Resumo}

A

s construções com paredes de terra destacam-se por suas propriedades higrotérmicas, que contribuem para a regulação desejável entre temperatura e umidade dos ambientes. Por outro lado, tais alvenarias estão sujeitas às manifestações patológicas, devido à ação da água das chuvas. O presente artigo avalia a eficiência do uso da mucilagem do cacto xique-xique (Pilosocereus gounellei) como tratamento superficial para paredes com blocos de terra comprimida (BTC). O objetivo é obter uma película protetora contra chuva, mas permeável ao vapor de água. Os ensaios realizados com corpos de prova cúbicos, extraídos de BTCs, possibilitaram comparações entre o tratamento proposto (TX), com diferentes concentrações de mucilagem, e uma resina acrílica impermeabilizante comercial (TR), tendo como controle amostras sem tratamento superficial (TC). Os resultados de absorção de água por capilaridade mostraram que a amostra TX com concentração 1:1 obteve comportamento similar à amostra TR, visto que, após 60 minutos de ensaio, TR, TX1:1 e TC tiveram um acréscimo de massa de $0,3 \mathrm{~g} / \mathrm{cm}, 0,5 \mathrm{~g} / \mathrm{cm}$ e $1,4 \mathrm{~g} / \mathrm{cm}$, respectivamente. A permeabilidade ao vapor de água para TX1:1 foi $5 \%$ maior do que TR e $6 \%$ menor do que TC. Após ensaios de calor e choque térmico com pequenas paredes, as amostras TX1:1 tiveram desempenho satisfatório.

Palavras-chave: BTC. Película. Vapor de água. Permeabilidade.

\begin{abstract}
Buildings with earth walls have outstanding hygrothermal properties, which contribute to a desirable regulation between temperature and humidity of environments. However, this type of masonry is vulnerable to pathologies due to the action of rainwater. This paper evaluates the efficiency of using the mucilage of the xique-xique cactus (Pilosocereus gounellei) as a surface treatment for walls made of compressed earth blocks (CEB). The aim is to obtain a protective film against rainwater, but which is permeable to water vapour. The tests performed with cubic specimens, extracted from CEBs, allowed comparisons between the proposed treatment (TX), using different

mucilage concentrations, and a commercial acrylic waterproofing resin (TR), using as control samples without any surface treatment (TC). The results of the water absorption by capillarity tests showed that the TX sample with 1:1 concentration had a similar behaviour to the TR sample, since after 60 minutes of testing, TR, TX1:1 and TC had a mass increase of $0.3 \mathrm{~g} / \mathrm{cm}^{2}, 0.5$ $\mathrm{g} / \mathrm{cm}^{2}$ and $1.4 \mathrm{~g} / \mathrm{cm}^{2}$ respectively. Water vapour permeability for TX1:1 was $5 \%$ higher than TR and 6\% lower than TC. After heat and thermal shock tests on small walls, the TX1:1 samples performed satisfactorily.
\end{abstract}

${ }^{1}$ Ana Beatriz Egypto Queiroga da Nóbrega

${ }^{1}$ Universidade Federal da Paraíba João Pessoa - PB - Brasil

${ }^{2}$ Aluísio Braz de Melo 2Universidade Federal da Paraíba João Pessoa - PB - Brasil

Recebido em 06/02/20 Aceito em 11/09/20
Keywords: CEB. Film. Water vapour. Permeability. 


\section{Introdução}

A indústria da construção civil transforma o ambiente natural em ambiente construído e, desse modo, caracteriza-se como uma das maiores consumidoras de recursos naturais (GUERRERO, 2016; MURMU; PATEL, 2018). No entanto, a dicotomia que a indústria da construção enfrenta no momento para se adequar às normas de sustentabilidade e continuar avançando configura-se em um dos grandes desafios atuais (PORTER et al., 2018). Nesse aspecto, destaca-se como alternativa a arquitetura sustentável ou bioarquitetura, que, segundo Niroumand, Zain e Jamil (2013), constitui-se aquela que se baseia nos requisitos locais, com utilização de materiais de construção e técnicas adequadas e acessíveis a cada contexto.

Segundo Eires (2012), as palavras sustentabilidade e ecologia têm sido utilizadas de modo generalizado e abusivo, e são aplicadas a todo material que possibilite reduzir minimamente o impacto ambiental. A autora sugere que, para classificar um produto como ecológico, alguns requisitos têm que ser considerados, tais como:

(a) material de origem natural e suficientemente permeável ao vapor de água (higroscopicidade), para manter um ambiente saudável;

(b) energia consumida para sua fabricação;

(c) custos de transporte;

(d) radioatividade emitida;

(e) impacto na saúde dos trabalhadores durante a fabricação ou na aplicação do produto;

(f) emissão de compostos orgânicos voláteis; e

(g) etc.

As construções com terra são empregadas em todo o mundo há milênios de anos, causando impactos ambientais insignificantes se comparados aos causados atualmente pela produção de tijolos cerâmicos, concreto e aço, por exemplo (FABBRI et al., 2019). No entanto, devido às técnicas utilizadas no passado terem se perdido ao longo do tempo, além de outras questões como preferência estética por outros materiais e sistemas construtivos, as construções de terra também são alvos de preconceitos, muitos desses relacionados à sua durabilidade, e sobretudo devido aos casos da doença de Chagas. Nesse contexto, conforme afirmam Morel e Charef (2019), alguns arquitetos da atualidade, conscientes da qualidade e abundância dessa matéria-prima, e usando as ideias de construtores do passado, que se beneficiaram durante anos de conhecimento empírico, propõem integrar esse material vernáculo ao atual sistema de construção. A principal motivação para o resgate dessas técnicas de construção com terra deve-se, sobretudo, às preocupações ambientais (EIRES; CAMÕES; JALALI, 2015). Para isso, os mais recentes estudos, que objetivam a produção de produtos com terra, de baixo custo, com reduzida energia de produção e economia circular (diretrizes que eram óbvias na construção vernácula), exigem inovações que possam ser facilmente implementadas no atual ambiente construído.

Entre as diversas técnicas de construção com terra, as quais possuem as vantagens relacionadas à possibilidade de o próprio usuário confeccionar os elementos construtivos, destaca-se uma das mais recentes, o BTC, que, assim como o adobe, tem a vantagem da comercialização do componente, diferente das técnicas de taipa de mão, taipa de pilão e terra ensacada. Outro aspecto que merece destaque no que diz respeito às construções de terra refere-se as suas propriedades térmicas e higrotérmicas, que contribuem para a regulação do conforto térmico dos ambientes e, portanto, para a exploração de mecanismos com funcionamento bioclimático, propiciando ambientes mais salubres (CAGNON et al., 2014; MAIA, 2016; MINKE, 2005). Porém, a desvantagem da terra, quando utilizada em vedações verticais externas, está relacionada ao desempenho frente à ação da água das chuvas. Segundo Heathcote (1995), o principal mecanismo que provoca a remoção do material da superfície das paredes de terra é a liberação da energia cinética associada a gotas de chuva, sobretudo o que ocorre em vedações externas expostas a ciclos repetidos de chuvas, seguidos por períodos de secagem. Caso não sejam utilizadas proteções ou tratamentos, pode ocorrer o desgaste na camada superficial, redução da resistência mecânica e até desagregação do material, demonstrando a sua vulnerabilidade (EIRES; CAMÕES; JALALI, 2014). Além disso, em situações em que não é possível utilizar beirais para proteger as vedações externas, ou em edificações com mais de um 
pavimento, são necessárias medidas de proteção como utilização de revestimentos ou impermeabilização. Nesse contexto, existem alternativas que minimizam o contato com a água das chuvas, através da adição de materiais, como, por exemplo, biopolímeros ${ }^{1}$, que melhorem a estabilização e coesão do solo, ou tratamentos superficiais que oferecem proteção e aumento da durabilidade. Contudo, ressalta-se que esses tratamentos superficiais não devem resultar em uma impermeabilização excessiva que anule o potencial do material de proporcionar uma regulação térmica do ambiente, ou seja, a sua capacidade de "respirar".

Eires, Camões e Jalali (2014) citam que, desde os tempos antigos, diferentes aditivos e adições são incorporados à terra com o propósito de estabilizar e aumentar sua durabilidade. Citam a cal e pozolanas e biopolímeros de origem vegetal e animal, muitos desses adicionados durante a hidratação da cal viva. Os autores apresentam vários exemplos relativos ao uso de biopolímeros na construção com terra em variadas partes do mundo. Na relação de biopolímeros incluem:

(a) incorporados ao solo na produção do adobe, para a construção da parede ou para a argamassa do reboco (estrume, palha, tuna, agave, dammar ${ }^{2}$, betume natural, sangue de animal, entre outros); e

(b) ou tintas com estrume e vagens de alforrobeira, nopal, látex ${ }^{3}$, etc. para pintura.

Os problemas de durabilidade recorrentes têm justificado, mais recentemente, diversas pesquisas com utilização de biopolímeros, visando melhorar a qualidade das construções em terra. Dove, Bradley e Patwardhan (2016) destacam que os biopolímeros são alternativas interessantes para o desafio atual de utilizar materiais mais sustentáveis e naturais, visto que são componentes orgânicos usados para modificar as propriedades de argilas, e potencialmente melhorar a ligação entre as partículas.

Udawattha et al. (2018) avaliaram o desempenho mecânico de blocos de terra estabilizados com diferentes dosagens de sete biopolímeros extraídos de plantas e árvores, selecionados a partir de técnicas vernáculas do Sri Lanka. A resistência à compressão seca mínima exigida foi $2 \mathrm{Mpa}$, de acordo com a norma local do estudo. Os resultados demonstraram que três dos sete biopolímeros estudados obtiveram melhor desempenho que os demais, como é o caso da resina de pinus (Pinoideae), a mucilagem das folhas do dawul kurudu (Neolitsea cassia) ${ }^{4}$ e o bagaço de cana-de-açúcar. A resistência máxima à compressão foi obtida na amostra com $15 \%$ de resina de pinus $(2,65 \mathrm{MPa})$.

Aranda-Jiménez e García-Izaguirre (2016) determinaram a resistência à abrasão de BTCs com adição de estabilizantes naturais (mucilagem do cacto Opuntia fícus e da Aloe vera barbadensis) e minerais (cimento e cal), cujos resultados deste estudo devem ser analisados com cautela. Nakamatsu et al. (2017) utilizaram carragenano ${ }^{5}$ como um bioaditivo para melhorar as propriedades físicas e mecânicas das construções com blocos de terra; os resultados demostraram que a sua incorporação na mistura durante a fabricação dos blocos, ou como revestimento em construções de terra existentes, melhoram seu comportamento, proporcionando impermeabilidade à água e resistência à erosão por ação da água de chuvas. Os resultados dos testes mecânicos também mostram uma considerável melhora na resistência à compressão e à tração quando o bioaditivo é incorporado durante o processo de fabricação dos blocos. Tatane et al. (2018) estudaram o efeito da adição do biopolímero, proveniente da casca de nozes de $\operatorname{argan}^{6}$ (PANS), no comportamento mecânico e térmico de BTCs com adição de 5\% e sem adição. As medições incluíram, dentre outros ensaios, o de absorção de água por capilaridade realizado no próprio bloco. Os resultados sugerem que a incorporação de PANS reduz a absorção capilar dos blocos estudados; a amostra estabilizada com cimento e $2 \%$ do biopolímero apresentou os melhores resultados de resistência a compressão $(3,12$ $\mathrm{MPa})$.

Também se incluem como biopolímeros as mucilagens provenientes de cactáceas, que contêm em sua composição polímeros, os quais formam capas protetoras sobre as superfícies sólidas (CHIAPPERO;

${ }^{1}$ Biopolímeros são polímeros orgânicos produzidos por seres vivos; podem ser de origem animal, vegetal ou mineral. Na construção civil são utilizados óleos, amidos, gomas, ceras, mucilagens, resinas de plantas, além do soro de leite, clara de ovo, excrementos de animais, entre outros.

${ }^{2}$ Resina natural proveniente de árvores da família Diopterocarpaceae

${ }^{3}$ Hevea euphorbiacex

${ }^{4}$ Neolitsea cassia, conhecida como dawul kurundu, é uma espécie de árvore da família Lauraceae muito encontrada no Sri Lanka.

${ }^{5}$ Carrageninas ou carragenanos são polissacarídeos obtidos a partir de extratos de algas marinhas vermelhas, conhecidas por algas carraginófitas, comuns nas costas de áreas oceânicas temperadas.

${ }^{6}$ Argania spinosa, gênero da família Sapotaceae, muito apreciada por seu óleo.

Potencial da mucilagem do cacto xique-xique como tratamento superficial para blocos de terra comprimida 
SUPISCHE, 2006). Conforme Sáenz et al. (2013), plantas da família das cactáceas possuem cladódios ${ }^{7}$ mucilaginosos. Nesse aspecto, essa produção de mucilagem nos cladódios é uma das principais características das cactáceas, a qual é composta por polissacarídeos complexos, que incham na presença de água e resultam em um produto com consistência viscosa que possui propriedades adesivas (SÁENZ; SEPÚLVEDA; MATSUHIRO, 2004; COLONETTI, 2012).

Segundo Inglese et al. (2017), em estudo publicado pela Food and Agriculture Organization (FAO), os cactos são considerados como o alimento do futuro. Apesar de a espécie Opuntia-ficus ser a mais utilizada para diversos fins, outras espécies são também estudadas. Contudo, é importante destacar que no processo de beneficiamento dos cactos para fins alimentícios são gerados resíduos, que podem ser utilizados como biopolímeros (fibras e/ou mucilagens) nas construções com terra, alcançando assim uma cadeia produtiva sustentável. Nesse sentido, parece interessante propor o aproveitamento da mucilagem, explorando a possibilidade de seu uso para o tratamento superficial das construções com terra. Estima-se que são necessárias, em média, $160 \mathrm{~g}$ desse resíduo para aplicação de cada demão do produto em $1 \mathrm{~m}$ de alvenaria de BTC.

Diante de tais considerações, o presente artigo apresenta um estudo experimental que avalia a utilização de mucilagem do cacto xique-xique (Pilosocereus gounellei), a fim de verificar o seu potencial como película protetora do BTC (tratamento superficial). Mais especificamente, nesse estudo, busca-se avaliar a redução da permeabilidade ao vapor de água, e melhoria da impermeabilidade a água dos BTCs, características desejáveis para assegurar a durabilidade, sem comprometer as propriedades higrotérmicas da parede de terra. Popularmente conhecida como xique-xique, essa espécie de cactácea, ou melhor, o resíduo gerado no processo de seu beneficiamento para fins alimentícios, foi escolhida para a realização desta pesquisa, sobretudo por se tratar de uma espécie amplamente encontrada no Nordeste do Brasil, em áreas do bioma Caatinga (MONTEIRO et al., 2015). Ademais, cabe ressaltar que não foram encontrados registros da utilização dessa espécie para tal fim.

\section{Materiais e métodos}

O tratamento superficial com mucilagem do cacto xique-xique em BTC é avaliado por meio de ensaios realizados em corpos de prova cúbicos e em pequenas paredes. Com os corpos de prova, realizam-se ensaios de permeabilidade ao vapor de água e de absorção de água por capilaridade; nas pequenas paredes, realiza-se o ensaio de choque térmico.

O estudo experimental é estruturado em seis etapas: extração da mucilagem do cacto xique-xique e sua caracterização físico-química; preparo dos corpos de prova; ensaios de permeabilidade ao vapor de água; ensaios de absorção de água por capilaridade; ensaios de calor e choque térmico em pequenas paredes; avaliação dos resultados.

\section{Extração da mucilagem do cacto xique-xique e caracterização físico-química}

Os cladódios do xique-xique com 2 anos de idade, em média, foram coletados em um município da região do bioma Caatinga do Nordeste brasileiro, em uma área de cultivo particular (coordenadas geográficas: W $7^{\circ} 15^{\prime} 32^{\prime \prime}$; S 36 14'24"). O estágio de maturidade dos cladódios foi definido com base no estudo realizado por Contreras-Padilla et al. (2016), que indicam que a mucilagem diminui com a maturidade (idade do vegetal). A coleta do material vegetal foi registrada no Sistema de Informação e Biodiversidade do Brasil (SISBIO) e no Sistema Nacional de Gestão de Patrimônio Genético e Conhecimento Tradicional Associado (SISGEN).

No laboratório, foram retirados os espinhos dos cladódios, seguido da lavagem com água corrente. Os cladódios foram então cortados e agrupados, segundo orientação de Bezerril (2017), como: cilindro vascular, talo central, cilindro vascular + talo central e casca (Figura 1a). Com exceção das cascas, as outras partes dos cladódios foram utilizadas em pesquisas com fins alimentícios; as cascas, que seriam descartadas, foram utilizadas para a extração da mucilagem objeto do presente estudo.

${ }^{7}$ Cladódio é o termo designado para um tipo de modificação caulinar, que consiste na presença de ramos nas vegetações, morfologicamente similares às folhas

162 Nóbrega, A. B. E. Q. da; Melo, A. B. de. 
Para obtenção da mucilagem, adaptou-se o procedimento adotado por Magalhães e Almeida (2010). Desse modo, em vez do vegetal inteiro, foram utilizadas apenas as cascas, que foram imersas em água utilizando duas diferentes proporções:

(a) $1 \mathrm{~kg}$ do vegetal para 1 litro de água (Figura 1b); e

(b) $1 \mathrm{~kg}$ do vegetal para 2 litros de água, mantendo-se por 2 dias com temperatura ambiente de $25 \pm 3{ }^{\circ} \mathrm{C} \mathrm{e}$ umidade relativa do ar de $60 \%$.

Após esse período, obteve-se a mucilagem com a separação da mistura através do auxílio de uma peneira (Figura 1c).

Com a finalidade de caracterizar a mucilagem do xique-xique foram realizados ensaios físico-químicos de cada dosagem (1:2 e 1:1), em triplicata, determinando-se a atividade de água, sólidos solúveis, pH, umidade, carboidratos, cinzas, acidez, viscosidade e cor, conforme metodologia a seguir:

(a) atividade de água (Aa) - determinada a uma temperatura de $25^{\circ} \mathrm{C}\left( \pm 4{ }^{\circ} \mathrm{C}\right)$, utilizando-se o equipamento AquaLab, CX-2, seguindo a metodologia descrita em seu manual;

(b) sólidos solúveis (Brix) - determinados utilizando refratômetro digital (Hanna, HI 96801);

(c) $\mathrm{pH}$ - realizada em potenciômetro digital (Quimis, Q 400, Diadema, São Paulo, Brasil);

(d) umidade - utilizando secagem em estufa a $105^{\circ} \mathrm{C}$, método descrito pela AOAC (ASSOCIATION..., 2012);

(e) carboidratos - a quantificação foi realizada com base no método fenol-sulfúrico, conforme Dubois et al. (1956);

(f) cinzas - obtidas com a incineração em mufla a $550^{\circ} \mathrm{C}$, até peso constante, método descrito pela $\mathrm{AOAC}$ (ASSOCIATION..., 2012);

(g) acidez - baseada na neutralização da amostra com solução padrão $\mathrm{NaOH} 0,1 \mathrm{~N}$, determinada por titulometria;

(h) viscosidade - baseado na determinação dos tempos de escoamento (t) das mucilagens, utilizando um viscosímetro capilar de Ostwald, segundo Cannon-Fenske, com capilar de número $52023 \mathrm{~mm}$ Schott, Modelo: AVS 350. A viscosidade cinemática foi determinada através da expressão: $\mathrm{V}=\mathrm{K}$. $\mathrm{t}$, onde a constante $(\mathrm{k}=0,2326 \mathrm{~mm} / \mathrm{s})$; e

(i) cor instrumental - realizada pelo sistema CIELab, sendo L (luminosidade), a* (verde - vermelho) e b* (azul - amarelo), utilizando o colorímetro Konica Minolta, CR 400.

A realização desses ensaios teve como objetivo estabelecer um padrão de caracterização, visto que diversos fatores influenciam essas variáveis, tais como: idade dos cladódios, local da coleta (clima da região), época da coleta, além dos diferentes métodos existentes para obtenção da mucilagem. Esses ensaios também possibilitam a comparação entre as diferentes dosagens ensaiadas, e com os resultados de outros autores que analisaram outras espécies de cactáceas.

\section{Preparo de corpos de prova}

Os ensaios para avaliar a alteração do comportamento higrotérmico em função do tratamento superficial com a mucilagem xique-xique foram realizados com corpos de prova cúbicos (com $5 \mathrm{~cm}$ de aresta) extraídos dos BTCs existentes no laboratório (Figura 2b). Esses blocos, com dimensões de $14 \mathrm{~cm} \mathrm{x} 10 \mathrm{~cm} \times 28 \mathrm{~cm}$ (largura x altura x comprimento), foram produzidos em 2015, com a utilização de uma prensa manual (Figura 2a).

Naquela época, após a moldagem dos blocos, eles foram acondicionados e protegidos da ação direta de sol, ventos e chuva, e cobertos com lona plástica, para garantir o processo de cura por, no mínimo, 7 dias. A maior parte desses blocos foi utilizada, em 2015, para construção de um protótipo. Os que restaram foram empilhados e mantidos em local coberto e protegido até 2018, quando se iniciou este projeto experimental As características dos BTCs produzidos em 2015 estão descritas no Quadro 1.

Os corpos de prova foram agrupados em 5 amostras (4 CPs por amostra) e identificados de acordo com o tratamento superficial aplicado, conforme indicado no Quadro 2. As amostras TC e TR são adotadas como referências para análise dos resultados. 
Com exceção da amostra TX1:1i, na qual os corpos de prova foram imersos na mucilagem por 30 minutos, os demais tratamentos superficiais foram realizados com o auxílio de um pincel com cerdas $25 \mathrm{~mm}$, aplicando-se duas demãos, executadas em sentidos cruzados, com um intervalo de 4 horas.

Figura 1 - Processo de obtenção da mucilagem xique-xique

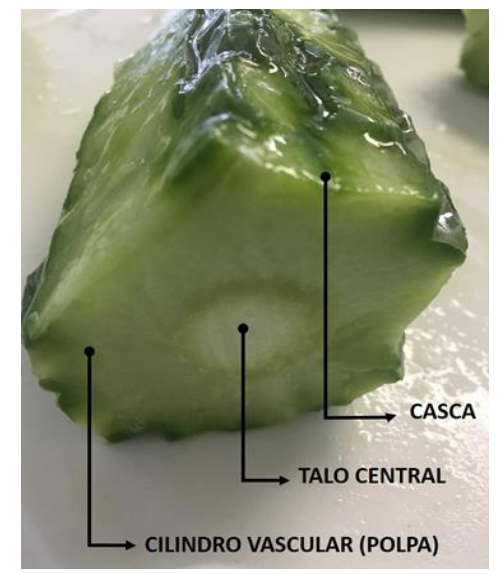

(a)

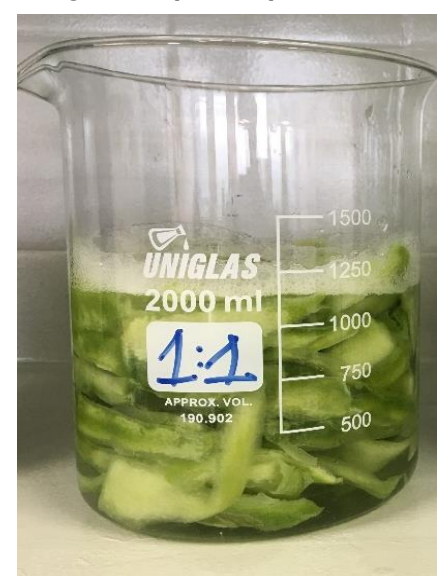

(b)

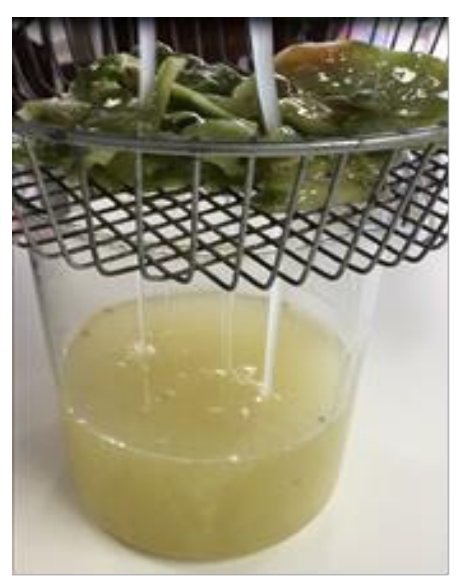

(c)

Figura 2 - BTC e corpos de prova

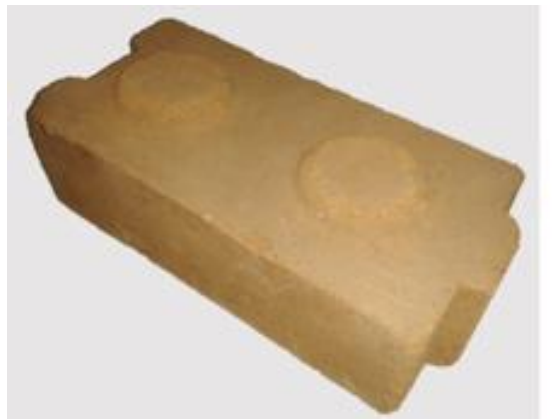

(a)

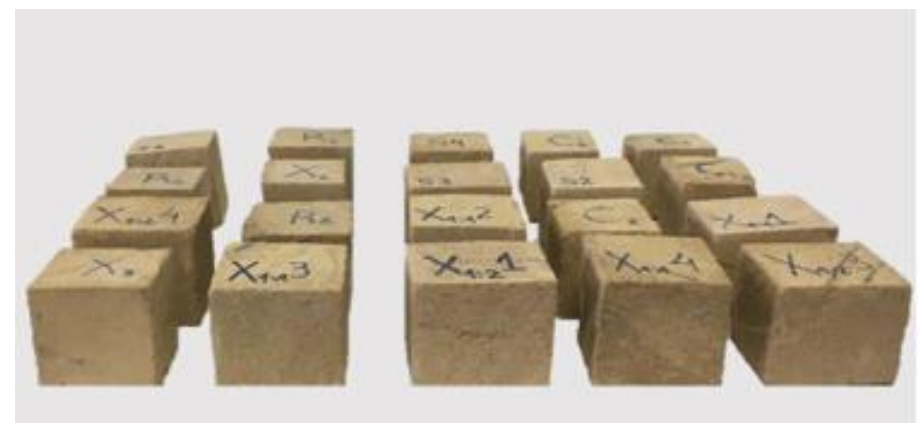

(b)

Quadro 1 - Características do BTC

\begin{tabular}{|c|c|c|c|}
\hline \multirow{8}{*}{ Materiais } & \multirow{6}{*}{ Solo } & Areia: $64 \%$ & \multirow{3}{*}{ NBR 7181 (ABNT, 2018) } \\
\hline & & Silte + argila: $35 \%$ & \\
\hline & & Pedregulho: $1 \%$ & \\
\hline & & Limite de liquidez: $22 \%$ & NBR 6459 (ABNT, 2017) ${ }^{*}$ \\
\hline & & Limite de plasticidade: $18 \%$ & NDP 7180 (APNT $20166^{* * *}$ \\
\hline & & Índice de plasticidade: $4 \%$ & NBK /180 (ABN1, 2016) \\
\hline & $\begin{array}{l}\text { Cimento } \\
\text { Portland }\end{array}$ & $\begin{array}{l}\text { CP II } 32 \text { RS: } 5 \% \text { em relação } \\
\text { e seca ao ar }\end{array}$ & de terra (solo) no estado solto \\
\hline & Água & $\begin{array}{l}\text { Potável, proveniente do sist } \\
\text { massa de terra, no estado solt }\end{array}$ & $\begin{array}{l}\text { bastecimento público: } 15 \% \text { em relação à } \\
\text { ao ar }\end{array}$ \\
\hline Produção & & $\begin{array}{l}\text { Mistura manual dos materiai } \\
\text { Moldagem dos blocos em má } \\
\text { Cura dos blocos: cobrimento }\end{array}$ & $\begin{array}{l}\text { tipo manual } \\
\text { plástica no interior do galpão }\end{array}$ \\
\hline BTC & & Massa do bloco $-5,35 \mathrm{~kg}$ & \\
\hline $\begin{array}{l}\text { Parâmetro } \\
\text { do bloco }\end{array}$ & aliados & $\begin{array}{l}\text { Absorção de água média aos } \\
\text { Resistência à compressão mé }\end{array}$ & $\begin{array}{l}\text { dal a } 11 \% \\
\text { dias igual a } 2,07 \mathrm{MPa}\end{array}$ \\
\hline
\end{tabular}

Nota: "a norma utilizada na época da produção dos blocos, a NBR 6459 (ABNT, 1984a), foi cancelada e substituída pela NBR 6459 (ABNT, 2017). "*a norma utilizada na época da produção dos blocos, a NBR 7180 (ABNT, 1984b), foi cancelada e substituída pela NBR 7180 (ABNT, 2016). 
Quadro 2 - Amostragem

\begin{tabular}{|c|c|c|}
\hline Tratamento superficial & Identificação da amostra & Proteção aplicada \\
\hline Controle & TC & sem aplicação \\
\hline Resina & TR & resina acrílica impermeabilizante industrializada \\
\hline Xique-xique 1 & TX1:1 & mucilagem 1:1(cacto: água) \\
\hline Xique-xique $1_{\text {imerso }}$ & TX1:1i & mucilagem 1:1(cacto: água) \\
\hline Xique-xique 2 & $\mathrm{TX} 1: 2$ & mucilagem 1:2(cacto: água) \\
\hline
\end{tabular}

\section{Determinação da permeabilidade ao vapor de água do BTC com diferentes tratamentos superficiais}

Os corpos de prova relativos às cinco diferentes amostras foram mantidos em sala climática $(50 \%$ UR/23 ${ }^{\circ} \mathrm{C}$ ) até estabilização da massa. Em seguida, foram submetidos a quatro ciclos sequenciais (24 horas de duração cada), com duas diferentes combinações de temperatura e umidade relativa $\left(35 \% \mathrm{UR} / 32{ }^{\circ} \mathrm{C}\right.$ e $80 \%$ $\mathrm{UR} / 20^{\circ} \mathrm{C}$ ), a fim de determinar o comportamento higrotérmico, ou seja, a permeabilidade ao vapor de água, que corresponde à variação de massa resultante da dessorção/adsorção de água (Quadro 3). Ao final de cada ciclo determinou-se a variação de massa, considerando a comparação com o ciclo anterior. Esse procedimento adotado para determinação da permeabilidade ao vapor de água baseou-se nos estudos realizados por Minke (2005), Cagnon et al. (2014) e Vares et al. (2017). Ressalta-se que os valores de temperatura e umidade relativa utilizados simulam um clima com elevada amplitude térmica e higrométrica, como é o caso típico da região do semiárido no Nordeste brasileiro.

O controle da temperatura do ar do ambiente de ensaio foi viabilizado pela opção de realizar no interior de uma câmara climática MA 415 Marconi. No caso do controle da umidade relativa do ar adotou-se o método descrito por Greenspan (1977), que descreve o uso de soluções salinas saturadas (Quadro 3). As soluções salinas foram colocadas na parte inferior de dessecadores com $25 \mathrm{~cm}$ de diâmetro, sendo os corpos de prova dispostos acima desse prato de porcelana padrão dos dessecadores (Figura 3). Para determinar a massa dos corpos de prova, utilizou-se uma balança semianalítica BG2000 Quimis. Equipamentos do tipo Datalogger (modelo UX100-003) foram colocados no interior de cada dessecador para assegurar os controles das temperaturas e umidade relativa do ar. Para análise dos resultados comparou-se as amostras TX (1:1, 1:1i e 1:2) com as referências (TC e TR), consideradas como parâmetros positivo e negativo, respectivamente.

\section{Determinação da absorção de água por capilaridade do BTC com diferentes tratamentos superficiais}

Os ensaios de absorção de água por capilaridade foram realizados com base no procedimento RILEM n. II.6 (RILEM, 1980). Após aplicar o tratamento superficial, os corpos de prova foram secos em estufa ventilada a $60{ }^{\circ} \mathrm{C}$, até se obter massa constante, considerada como valor da massa seca. Em seguida, os corpos de prova foram colocados em recipientes, caixas de plástico, parcialmente imersos em uma lâmina de água com espessura correspondente a $5 \mathrm{~mm}$ acima da sua face inferior. Os recipientes foram tampados para evitar a evaporação da água, durante os intervalos de medição. A periodicidade da determinação de massa foi realizada conforme adotado por Azevedo (2013), ou seja, a cada $1 \mathrm{~min} ; 3 \mathrm{~min} ; 5 \mathrm{~min} ; 10 \mathrm{~min} ; 15 \mathrm{~min} ; 30$ min; $60 \mathrm{~min} ; 8 \mathrm{~h}$ e $24 \mathrm{~h}$. Com os resultados obtidos, através da média das massas dos corpos de prova, obteve-se a curva de absorção de água por capilaridade, que expressa a quantidade de água absorvida por unidade de superfície $(\mathrm{g} / \mathrm{cm})$, em função do tempo decorrido durante os ensaios. Para análise dos resultados comparou-se o comportamento das amostras TX (1:1, 1:1i e 1:2) com as referências (TC e TR).

\section{Ensaio de calor e choque térmico em pequenas paredes de BTC}

Dentre os ensaios de envelhecimento acelerado para análise da durabilidade de sistemas de proteções nas superfícies das vedações, destaca-se o ensaio de calor e choque térmico. Esse ensaio é interessante pelo fato de simular a ação da chuva e do sol, incidindo diretamente nas vedações externas das edificações. O ensaio de choque térmico executado seguiu o procedimento estabelecido na NBR 15575-4 (ABNT, 2013), sendo realizado no interior de uma câmara de choque térmico, existente no laboratório.

$\mathrm{O}$ ensaio foi realizado em três pequenas paredes de BTC, com dimensões de $14 \mathrm{~cm}$ x $70 \mathrm{~cm}$ x $70 \mathrm{~cm}$ (largura $\mathrm{x}$ altura $\mathrm{x}$ comprimento). Os blocos foram assentados com argamassa fluida de terra, cimento a água. À terra passante na peneira de $2,4 \mathrm{~mm}$, a mesma utilizada para fabricação do BTC, adicionou-se $10 \%$ de cimento 
Portland em relação à massa da terra e água, até se atingir consistência fluida. Como o BTC utilizado é intertravado, o processo de assentamento permite menor uso de argamassa (Figura 4a).

Depois de 28 dias, as pequenas paredes receberam os tratamentos superficiais TC; TR e TX1:1 (Figuras 4b e 4c). A opção por adotar o tratamento TX1:1 deve-se à obtenção dos melhores resultados nos ensaios de caracterização físico-química, absorção capilar e comportamento higrotérmico. As aplicações dos dois tratamentos superficiais foram realizadas com o auxílio de trinchas com cerdas $100 \mathrm{~mm}$, aplicando-se duas demãos em sentidos cruzados, com intervalo de 4 horas.

Depois de 10 dias da aplicação do tratamento superficial, tiveram início os ensaios de calor e choque térmico nas pequenas paredes. A sequência da realização dos ensaios foi a seguinte: inicialmente a pequena parede TR; 24 horas depois, a pequena parede TC; e 48 horas depois, a pequena parede TX1:1. Todas elas foram submetidas a 10 ciclos automáticos, contínuos e alternados entre calor e aspersão com água, a fim de produzir o choque térmico. Cada ciclo teve início com a temperatura superficial de $27 \pm 3{ }^{\circ} \mathrm{C}$ e, durante a ação do calor por 60 minutos diretamente em uma das faces, atingiu-se a temperatura superficial de $80 \pm 3$ ${ }^{\circ} \mathrm{C}$, quando se manteve neste patamar por 1 hora. Imediatamente após a suspensão do calor, resfriou-se por 15 minutos a mesma face, através de jatos de água aspergidos em sua superfície, até atingir a temperatura superficial inicial de $27 \pm 3{ }^{\circ} \mathrm{C}$. Dessa forma, cada ciclo teve duração de 135 minutos e, no total, os 10 ciclos contínuos de aquecimento e molhagem (calor e choque térmico) tiveram duração de 1.350 minutos para cada amostra de pequena parede, conforme apresentado na Figura 5.

$\mathrm{O}$ aquecimento foi realizado com auxílio de quatro resistências blindadas, instaladas em um painel metálico, com potência de $750 \mathrm{~W}$ cada, totalizando $3.000 \mathrm{~W}$. O esfriamento foi realizado por aspersão de água através de uma tubulação de CPVC perfurada, instalada horizontalmente na altura equivalente ao topo das pequenas paredes, permitindo a sua completa molhagem (Figuras 6a e 6b). A tubulação foi conectada a um reservatório que possui isolamento térmico, propiciando que a temperatura da água utilizada (cerca de 200 litros) mantivesse constante ao longo dos 10 ciclos do ensaio.

Quadro 3 - Condições dos ciclos para determinação do comportamento higrotérmico

\begin{tabular}{|c|c|c|l|}
\hline Ciclo & Umidade (\%) & Temperatura $\left({ }^{\circ} \mathbf{C}\right)$ & \multicolumn{1}{c|}{ Sal } \\
\hline $1^{\circ}$ e $3^{\circ}$ (dessorção) & 35 & 32 & cloreto de magnésio $\left(\mathrm{MgCl}_{2}\right)$ \\
$2^{\circ}$ e $4^{\circ}$ (adsorção) & 80 & 20 & cloreto de potássio $(\mathrm{KCl})$ \\
\hline
\end{tabular}

Figura 3 - Câmara climática (controle da temperatura) e dessecadores com corpos de prova (controle da umidade com soluções salinas saturadas)

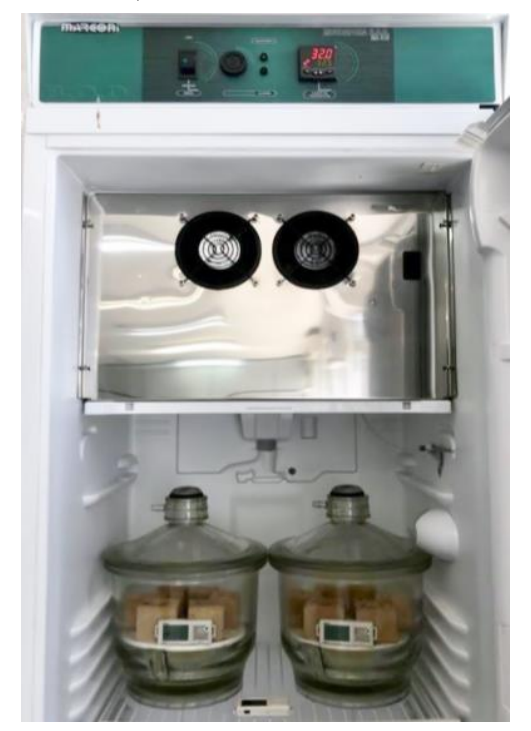

166 Nóbrega, A. B. E. Q. da; Melo, A. B. de. 
Figura 4 - Processo de confecção das pequenas paredes e aplicação do tratamento superficial

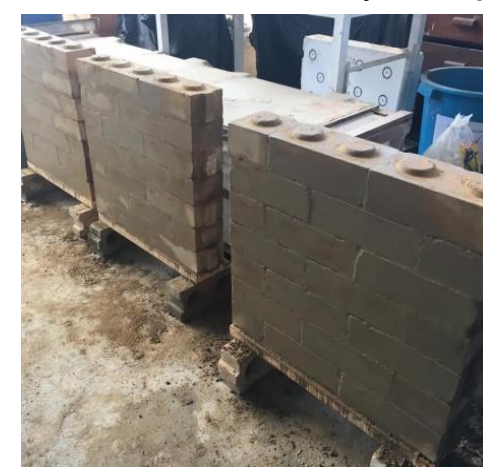

(a)

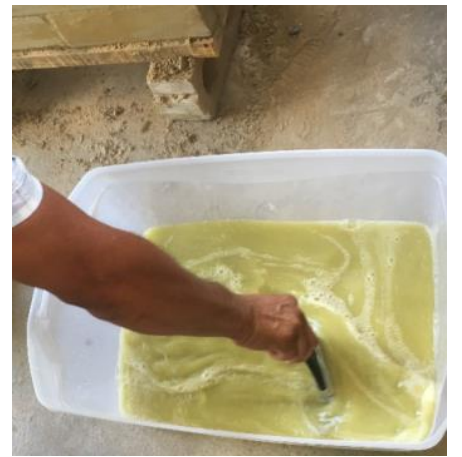

(b)

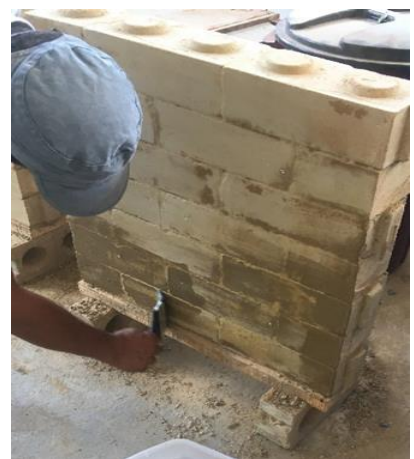

(c)

Figura 5 - Ciclos de calor e choque térmico realizado nas pequenas paredes

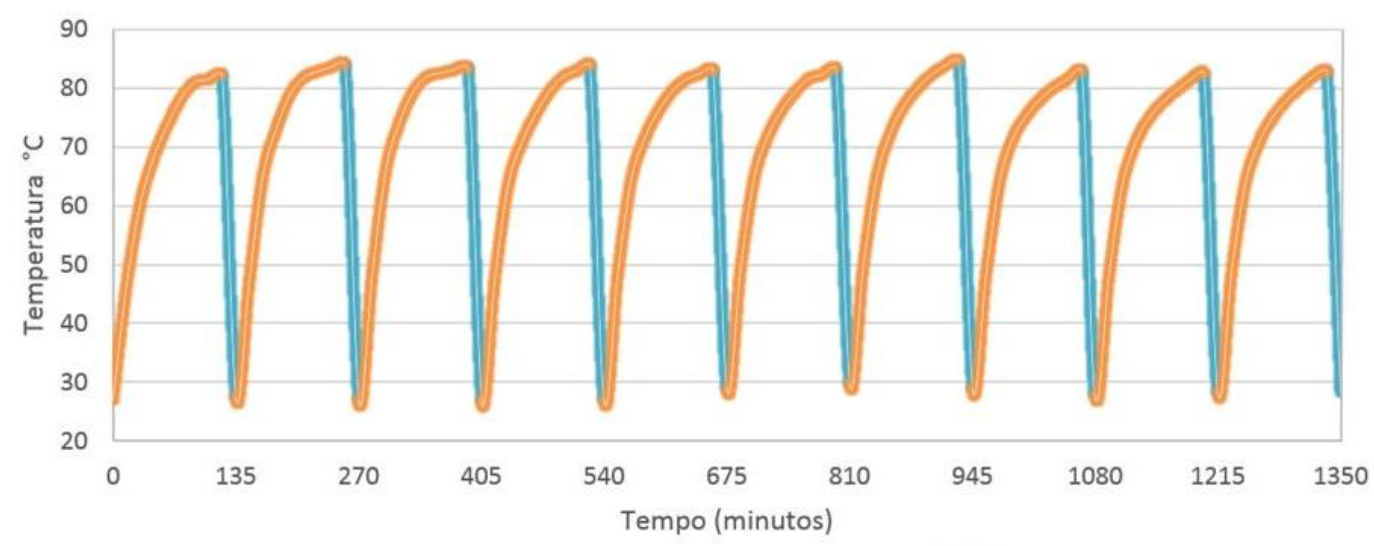

Calor Choque térmico (molhagem)

Figura 6 - Vista do espaço interno da câmara para ensaios de calor e choque térmico

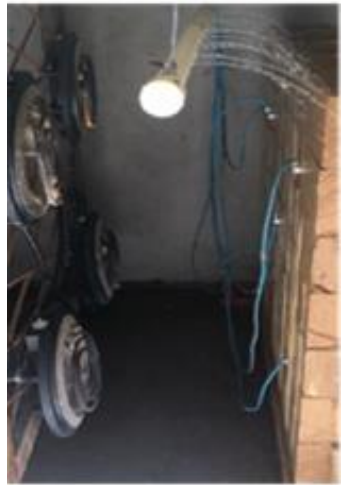

(a)

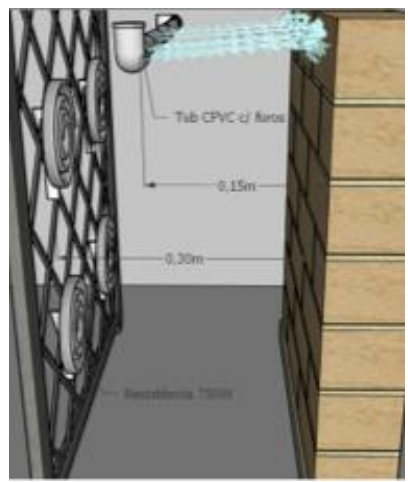

(b)

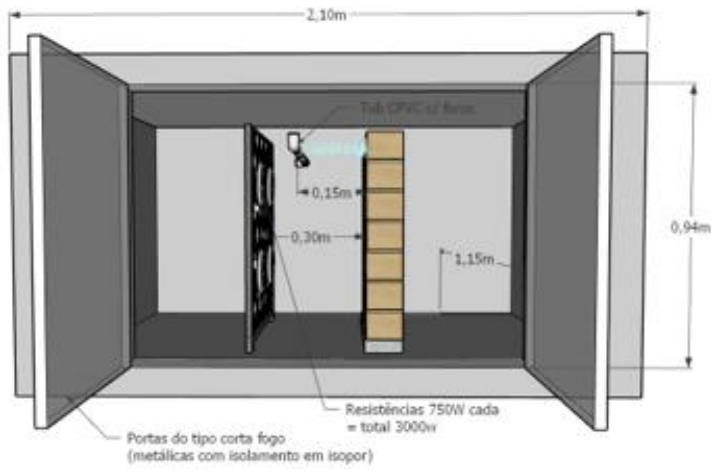

(c)

O acesso à câmara dá-se através de uma porta do tipo corta fogo (construídas com duplas chapas metálicas e preenchimento entre elas com placas de isopor) com duas folhas, sendo instalada veda fresta de borracha flexível na interface entre as folhas e os batedores. A Figura 6 apresenta uma imagem (Figura 6a) e um desenho esquemático (Figura 6b) com os detalhes da instrumentação com termopares na superfície da pequena parede, bem como as correspondentes distâncias entre ela e as fontes de calor e de água. Adicionalmente, apresenta-se outro desenho esquemático (Figura 6c), no qual são vistas as dimensões internas da câmara utilizada para ensaios de calor e choque térmico.

Cabe destacar que, durante o ensaio, os 10 ciclos foram contínuos e controlados automaticamente por um sistema elétrico, composto basicamente pelos seguintes equipamentos: 
(a) termostato;

(b) contactores;

(c) termopar e timer, que foram conectados entre si e nas resistências (fonte de calor); e

(d) também válvula solenoide, para regular o fluxo da água.

Esse sistema possibilitou maior controle na reprodução dos mesmos ciclos de calor e choque térmico com todas as pequenas paredes, além de permitir maior rapidez nos ensaios. Cinco sensores de temperatura foram instalados na superfície da pequena parede que simula a face externa da alvenaria durante o teste. Os sensores de temperatura utilizados foram termopares do tipo $\mathrm{T}$ (cobre + constantan), sendo as outras extremidades conectadas a um sistema de aquisição de dados (840AMX), que possibilitou a coleta das informações e registro das temperaturas em todos os ciclos de aquecimento e resfriamento (molhagem).

Ao final dos ensaios foram feitos registros fotográficos para identificar ocorrência de falhas (como fissuras, destacamentos, empolamentos ou descoloração), ou de outros danos que pudessem sugerir comprometimento da durabilidade dos dois tratamentos comparados (TR e TX1:1). Análises comparativas entre as pequenas paredes, ao término do ensaio, visando identificar a presença e concentração de umidade, foram feitas com uso de imagens termográficas, produzidas por uma câmera termográfica, modelo FLIR B400 da FLIR SYSTEMS. As imagens produzidas foram tratadas com o auxílio do software FLIR Tools, que permite medir temperaturas em determinados pontos ou áreas, alterar a paleta de cores ou até ajustar parâmetros como a emissividade, umidade relativa e temperatura.

\section{Resultados e discussões}

\section{Características da mucilagem xique-xique}

A Tabela 1 apresenta os valores médios das propriedades físico-químicas da mucilagem xique-xique obtida a partir das duas diferentes dosagens (cacto:água). Como era esperada, a menor concentração de água (1:1) utilizada promoveu menor teor de umidade e, consequentemente, maior quantidade de carboidratos, mais viscosidade e efeito na cor do produto final. Quanto maior a concentração de nutrientes e carboidratos na mucilagem, maior poderão ser suas propriedades funcionais, como impermeabilizantes e elásticas, em resposta a sua maior disponibilidade de polissacarídeos hidrocolóides (VARGAS-RODRIGUES et al, 2016). Algumas pesquisas indicam que a composição principal desse composto consiste em seis açúcares neutros: arabinose, galactose, ramnose, xilose, ácido urônico e ácido galacturônico (LEÓN-MARTINEZ; MÉNDEZ-LAGUNAS; RODRIGUES-RAMIREZ, 2010).

A maior viscosidade na dosagem 1:1, que é mais concentrada, permite melhor trabalhabilidade (impressão tátil-visual) durante a aplicação, em comparação com a dosagem 1:2, que apresenta consistência mais líquida. Apesar de não existir um valor ideal para a viscosidade desse tipo de produto para proteção superficial, sobretudo de origem orgânica (vegetal), um fluído com viscosidade muito baixa ou muito alta pode ser um fator dificultante no processo de aplicação nas vedações.

Tabela 1 - Valores médios das variáveis físico-químicas para as duas dosagens (concentrações) da mucilagem do xique-xique testadas

\begin{tabular}{c|c|c}
\hline \multirow{2}{*}{ Variáveis } & \multicolumn{2}{|c}{ Concentrações $^{* *}$} \\
\cline { 2 - 3 } & $\mathbf{1 : 1}$ & $\mathbf{1 : 2}$ \\
\hline Umidade (\%) & $99,09 \pm 0,00$ & $99,37 \pm 0,00$ \\
Carboidratos (\%) & $0,21 \pm 0,00$ & $0,09 \pm 0,00$ \\
Cinzas (\%) & $0,38 \pm 0,01$ & $0,35 \pm 0,02$ \\
Acidez (\%) & $0,76 \pm 0,05$ & $0,51 \pm 0,00$ \\
Atividade de água & $0,92 \pm 0,02$ & $0,93 \pm 0,02$ \\
SST ( ${ }^{\circ}$ Brix) & $0,90 \pm 0,20$ & $0,60 \pm 0,20$ \\
pH & $5,05 \pm 0,00$ & $5,08 \pm 0,00$ \\
Viscosidade (mm /s) & $3,79 \pm 0,06$ & $2,26 \pm 0,02$ \\
Cor instrumental & & \\
L* luminosidade & $13,93 \pm 0,29$ & $24,85 \pm 0,87$ \\
$\mathrm{a}^{*}$ (verde - vermelho) & $-0,04 \pm 0,02$ & $-0,07 \pm 0,03$ \\
$\mathrm{~b}^{*}$ (azul - amarelo) & $0,41 \pm 0,02$ & $0,19 \pm 0,08$ \\
\hline
\end{tabular}

Nota: "coordenadas cromáticas (sistema CIELab).

168 Nóbrega, A. B. E. Q. da; Melo, A. B. de. 
Os resultados obtidos para o $\mathrm{pH}$ da mucilagem aproximam-se dos citados por Soria et al. (2015), em seu estudo com a cactácea da espécie Opuntia amyclaea Tenore, como também dos descritos por ContrerasPadilla et al. (2016), estudando a mucilagem de Opuntia ficus-indica var. redonda, que confirmaram ser o produto final ligeiramente ácido, obtendo-se valores entre 5,5 e 6,0. Os valores obtidos para cor sendo L (luminosidade), a* (verde - vermelho) e b* (azul - amarelo), apresentaram diferenças entre os tratamentos estudados, o que pode ser explicado porque as soluções de maior viscosidade tendem a ser menos translúcidas, indicando tonalidade verde-amarelada no produto final.

Conforme afirmam Sepúlveda et al. (2007), não existe uma padronização nos processos de extração da mucilagem, visto que diferentes pesquisadores têm utilizado distintos métodos, dificultando assim uma comparação entre os resultados devido à influência no rendimento e composição química das mucilagens. Alguns estudos com mucilagens em forma de pó são relatados, obtidas por processo de extração com solventes, para as quais são observadas variações na composição, explicadas pelas diferenças do material vegetal utilizado para extração (diferentes espécies, condições de cultivo, estágios de maturidade, etc.), bem como pelo método aplicado para a extração da mucilagem (ESPINO-DÍAZ et al., 2010; RODRÍGUEZGONZÁLEZ et al., 2014). Além disso, os dados da literatura são escassos no que concerne à composição química da mucilagem da espécie de cactácea estudada, bem como ao método de obtenção utilizado, e à maioria dos trabalhos citam estudos realizados com outras cactáceas, principalmente com os gêneros Opuntia e Nopalea.

\section{Permeabilidade ao vapor de água}

O comportamento higrotérmico dos BTCs pode ser analisado a partir da permeabilidade ao vapor de água, comparando os resultados obtidos em função do tratamento superficial aplicado em cada amostra. O gráfico da permeabilidade ao vapor de água é apresentado na Figura 7, no qual os diferentes tratamentos superficiais são comparados, em função da variação de massa dos corpos de prova ao longo dos 4 ciclos intercalados de dessorção e adsorção (com variações de temperatura e umidade relativa do ar).

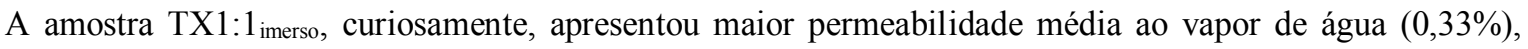
resultando na variação de massa em torno de $0,14 \%$ maior do que $\mathrm{TR}$, que apresentou a menor variação de massa entre todas comparadas $(0,19 \%)$. Tal resultado confirma que o tratamento com resina acrílica impermeabilizante (TR) cria uma barreira no corpo de prova, diminuindo a sua capacidade de "respirar".

A comparação da permeabilidade ao vapor de água entre as amostras TC $(0,30 \%)$ e TX1: $1_{\text {imerso }}(0,33 \%)$ demostra que tiveram comportamentos parecidos, embora com variação de massa $0,03 \%$ menor para TC, o que indica que TX1: $1_{\text {imerso }}$ gera maior permeabilidade ao vapor de água quando comparado com TC, que não teve nenhum tratamento superficial. O fenômeno não foi suficientemente compreendido, necessitando investigações adicionais, no futuro, sobre o caso específico. A amostra TX1:2 (0,27\%) se aproximou mais do comportamento da amostra controle TC, e teve variação $0,08 \%$ maior que a amostra TR. A amostra TX1:1 (0,24\%) teve uma variação 0,05\% maior do que a da TR, indicando que o tratamento superficial com mucilagem xique-xique, comparativamente à resina acrílica impermeabilizante, mantém maior permeabilidade, com potencial de preservar melhor a capacidade do material ser permeável ao vapor de água, e, consequentemente, regular a umidade do ambiente construído.

Nesse aspecto, pode-se inferir que os tratamentos superficiais realizados com mucilagem do xique-xique, nas suas diferentes dosagens e formas de aplicação, demonstram comportamento satisfatório se comparados à amostra TR, visto que, em um clima com as características de variação de temperatura e umidade simuladas no ensaio, as vedações de terra, que vierem a ser submetidas a esses tratamentos superficiais, mantiveram as suas características higrotérmicas. Ressalta-se, ainda, a dificuldade em comparar os resultados com outros estudos, visto que, conforme afirmam Laborel-Préneron et al. (2016), são escassos os dados sobre as características higrotérmicas de construções com terra que utilizam biopolímeros.

\section{Absorção de água por capilaridade}

A Figura 8 apresenta a absorção de água por capilaridade para as amostras submetidas aos diferentes tratamentos superficiais. Pode-se observar que a amostra TR apresenta menor absorção de água, sobretudo nos primeiros momentos do ensaio. Contudo, aquelas que receberam os tratamentos com a mucilagem xique-xique apresentaram absorção de água com valores intermediários entre os que foram tratados com resina acrílica impermeabilizante (TR) e os de controle (TC), sem tratamento superficial. Cabe destacar que o resultado obtido da amostra com mucilagem xique-xique, na dosagem mais concentrada (TX1:1), 
apresentou comportamento mais próximo da TR, adotada como amostra de referência em termos de eficiência nesse quesito.

Os maiores valores de ganho de massa das amostras, correspondente à água absorvida por capilaridade, como era esperado, ocorreu para a amostra TC, de controle. Após 60 minutos de ensaio, enquanto a amostra TC teve o acréscimo da ordem de $1,4 \mathrm{~g} / \mathrm{cm}$, as amostras TR e TX1:1 tiveram acréscimos de apenas 0,3 $\mathrm{g} / \mathrm{cm}$ e $0,55 \mathrm{~g} / \mathrm{cm}$, respectivamente. A Figura 9 representa, visualmente, a ascensão capilar da água nas amostras. Confirma-se que as amostras TC, TX1:1i e TX1:2 tiveram ascensão capilar mais rápida do que TR e TX1:1, corroborando os resultados do acréscimo de massa apresentados na Figura 8.

Portanto, pode-se afirmar que o esperado efeito de proteção superficial, em relação ao contato com a água, é da mesma ordem de grandeza para ambos os tipos de tratamentos aqui comparados, a resina comercial acrílica impermeabilizante (TR) e a mucilagem xique-xique (TX1:1), principalmente nas primeiras horas de ensaio. Esse resultado indica que a mucilagem xique-xique, especialmente a de dosagem 1:1 (cacto:água), obteve o melhor comportamento dentre os tratamentos superfícies com mucilagem xique-xique, e sobretudo quando comparada à amostra sem tratamento (TC).

Figura 7 - Permeabilidade ao vapor de água de BTCs com diferentes tratamentos superficiais

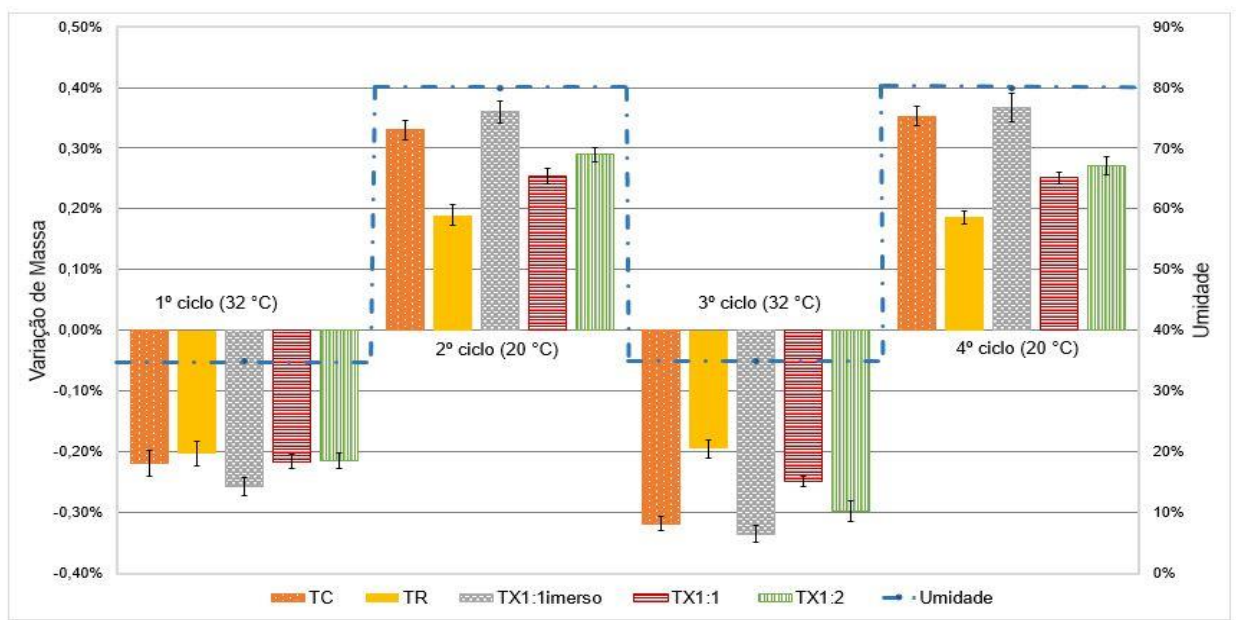

Figura 8 - Absorção de água por capilaridade das amostras de BTC com diferentes tratamentos superficiais

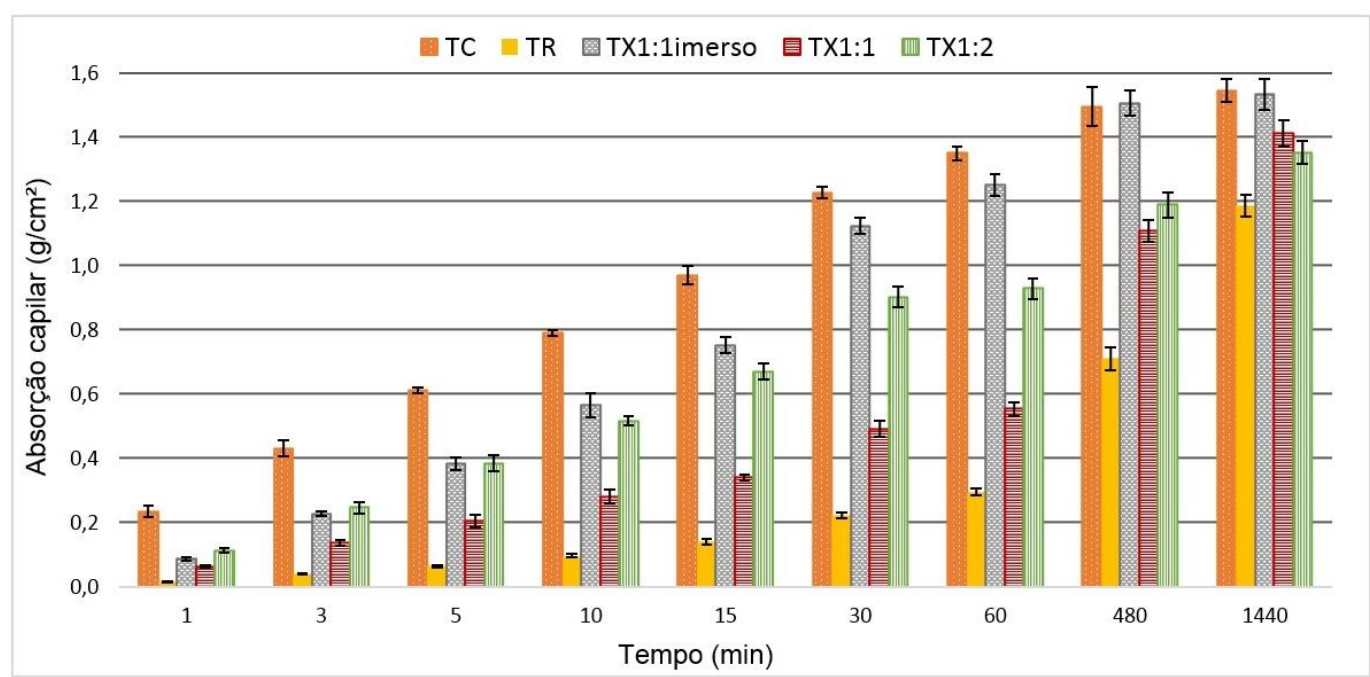

170 Nóbrega, A. B. E. Q. da; Melo, A. B. de. 


\section{Ação de calor e choque térmico}

A avaliação do envelhecimento acelerado dos tratamentos superficiais testados nas amostras de pequenas paredes de BTC foi baseada na reprodução de ciclos alternados de molhagem e secagem. Antes e após a realização do ensaio, foi feita a análise visual e com registros fotográficos das superfícies das pequenas paredes, a fim de identificar eventuais manifestações patológicas, ou quaisquer alterações decorrentes dos 10 ciclos de ação do calor e choque térmico.

A Figura 10 apresenta as imagens comparativas da pequena parede TC, antes (Figura 10a) e após o ensaio (Figura 10b). Observa-se um desgaste superficial localizado com aparecimento de manchas brancas, além de áreas mais escuras que indicam concentrações diferenciadas de umidade.

As imagens apresentadas na Figura 11 permitem comparar o comportamento da pequena parede TR, na qual foi aplicada a resina comercial acrílica. Pode se observar que, apesar de seguidas as instruções de aplicação do produto, fornecidas pelo fabricante da resina, surgiram bolhas em diversos pontos da superfície da pequena parede, o que indica algum comprometimento da proteção superficial. Por outro lado, é perceptível como a aparência em termos de cor da pequena parede TR, após o ensaio, é mais homogênea comparada à imagem da TC, o que indica que a TR pode ter tido alguma absorção de água, contudo parece mais uniforme em toda a sua superfície.

A Figura 12 apresenta as imagens comparativas (antes e após o ensaio, respectivamente) da pequena parede TX1:1, na qual foi aplicado o tratamento com mucilagem xique-xique. Observa-se novamente o surgimento de algumas manchas esbranquiçadas, porém é notável como a pequena parede TX1:1 parece ter um comportamento superior ao da amostra TC, sendo possível identificar menores pontos de concentração de umidade, devido à molhagem durante os ciclos de calor e choque térmico, marcadas pelas manchas escuras.

O resultado indica que, nesse caso, pode ser necessária a aplicação de maior número de demãos para melhorar sua eficiência na proteção da superfície do BTC em relação à absorção de água.

Destaca-se ainda que praticamente não houve formação de bolhas, como aquelas vistas na pequena parede TR. Assim, o potencial da aplicação do tratamento superficial da mucilagem do xique-xique em paredes executadas com BTC pode ser confirmado, inclusive contando com a possibilidade de proporcionar durabilidade ao sistema de proteção superficial.

Figura 9 - Desenho esquemático da ascensão capilar da água de diferentes amostras após 60 minutos de ensaio

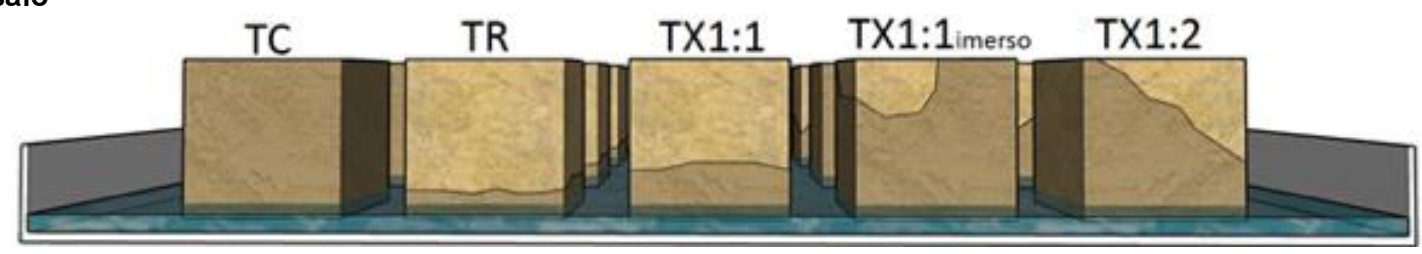

Figura 10 - Pequena parede TC antes e após os ciclos de calor e choque térmico

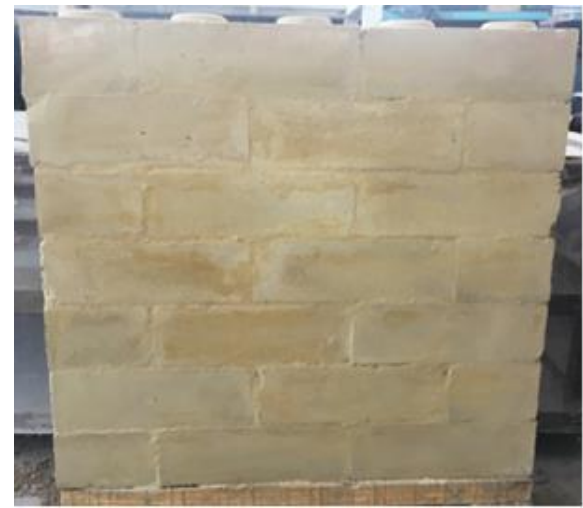

(a) Antes do ensaio

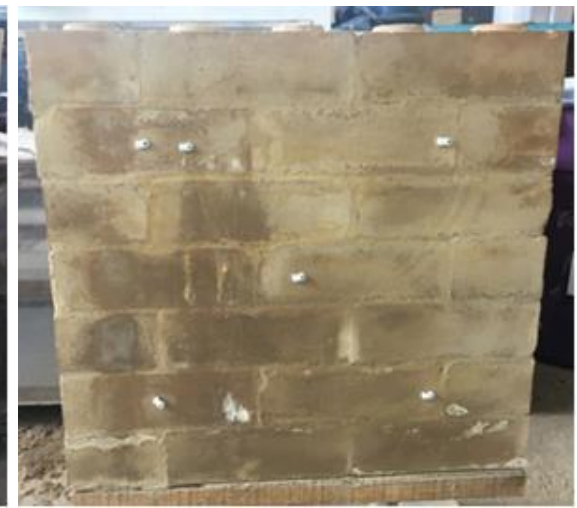

(b) Após o ensaio 
Figura 11 - Pequena parede TR antes e após os ciclos de calor e choque térmico

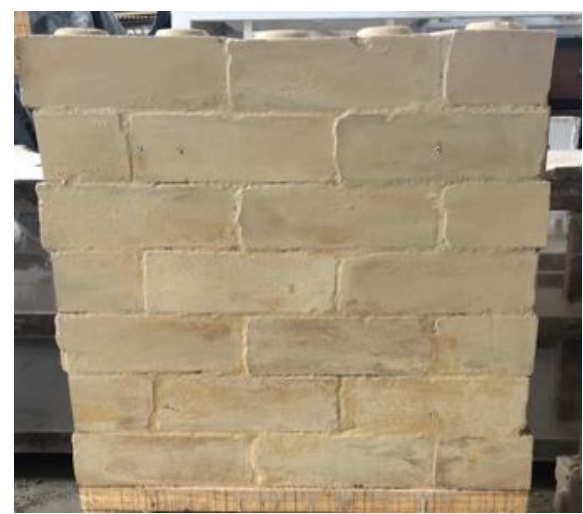

(a) Antes do ensaio

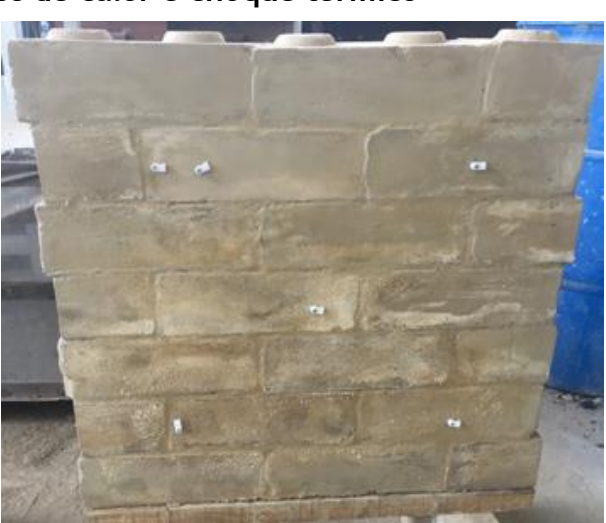

(b) Após o ensaio

Figura 12 - Pequena parede TX1:1 antes e após os ciclos de calor e choque térmico

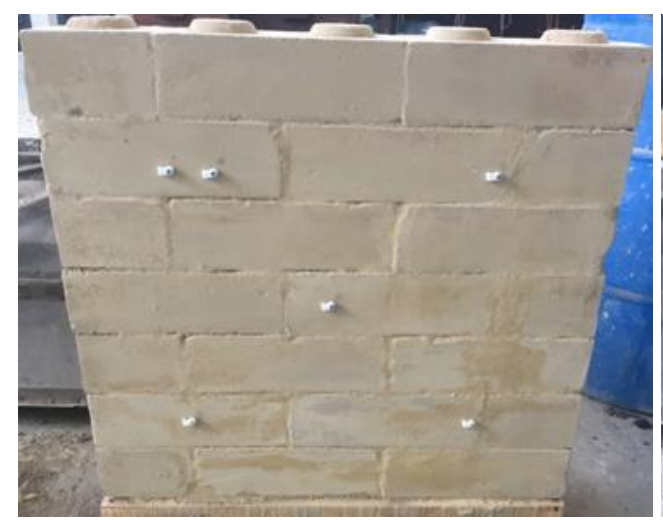

(a) Antes do ensaio

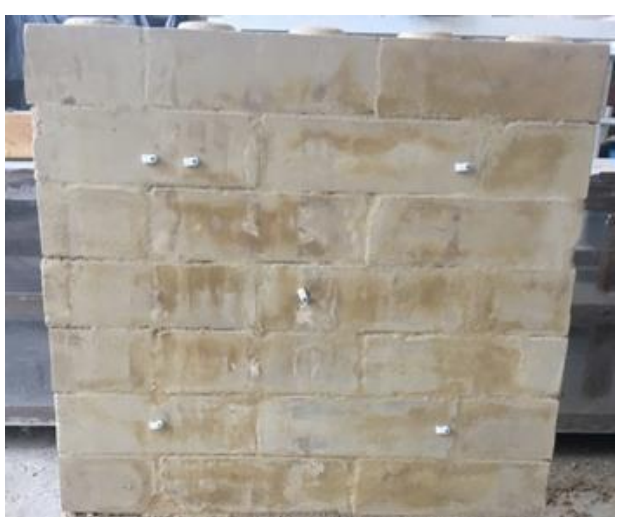

(b) Após o ensaio

Na Figura 13a é apresentada a imagem das amostras após a finalização dos ciclos. Na Figura 13b é apresentado o termograma, desse mesmo momento, em que é possível perceber as diferentes temperaturas e manchas de umidades superficiais entre as três pequenas paredes, sendo as amostras TX1:1, TC e TR fotografadas com 1 dia, com 2 dias e com 3 dias, após encerrados os respectivos ensaios de calor e choque térmico. A amostra TC apresenta-se com diferente coloração, indicando maior presença de umidade. As amostras TX1:1 e TR apresentam temperaturas superficiais semelhantes; a TX1:1 apresenta-se menos úmida, o que indica menor absorção, ou perda mais rápida da água acumulada durante o ensaio.

Deve-se destacar os diferentes tempos de espera de cada amostra, após a finalização do ensaio, para se realizar a imagem termográfica, bem como o fato de terem ficado protegidas sob um galpão coberto no laboratório, que tem pé-direito duplo. A amostra TC, mesmo depois de 2 dias do encerramento do ensaio, ainda se apresentava bastante úmida.

\section{Conclusão}

Com base no estudo realizado, conclui-se que o uso da mucilagem do cacto xique-xique para tratamento superficial da alvenaria de BTC melhora sua durabilidade e proteção quanto à ação da água, sem redução significativa da higroscopicidade característica do material. Essa conclusão fundamenta-se nas análises dos resultados alcançados no experimento constituído por quatro parâmetros: caracterização físico-química da mucilagem, e permeabilidade ao vapor de água, absorção de água por capilaridade e envelhecimento acelerado dos BTCs com diferentes tratamentos superficiais.

A caracterização físico-química da mucilagem do cacto xique-xique, obtida a partir de diferentes proporções (cacto:água), revelou que a menor incorporação de água (1:1) utilizada no preparo da mucilagem promoveu maior quantidade de carboidratos e mais viscosidade. 
Figura 13 - Imagem e termograma das pequenas paredes TX1:1, TC e TR após os ensaios

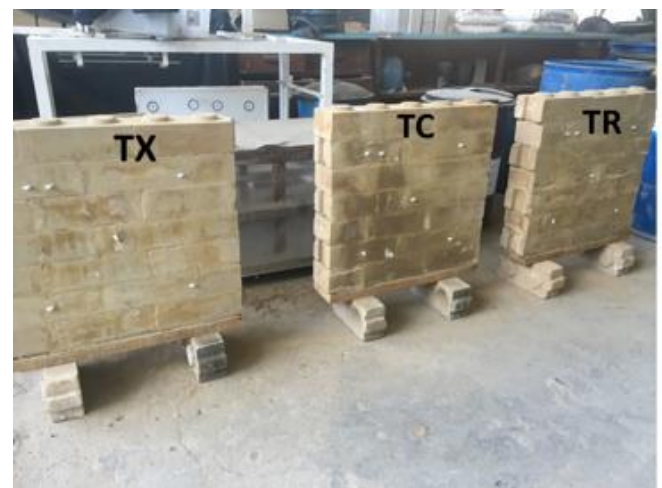

(a)

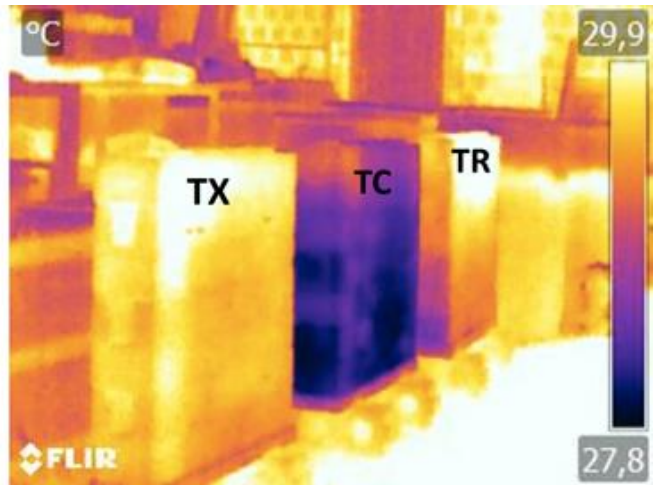

(b)

A permeabilidade ao vapor de água foi menor nas amostras que receberam o tratamento com resina acrílica (TR), o que confirma a criação de uma barreira superficial no BTC, diminuindo a sua capacidade de "respirar". A aplicação superficial da mucilagem xique-xique (TX1:1) no BTC reduziu até 5\% o efeito de barreira na superfície ao vapor de água do ambiente, comparada ao comportamento da resina acrílica. Esse fato indica que o BTC com esse tratamento superficial pode preservar, ainda que parcialmente, a sua característica higrotérmica.

A absorção de água por capilaridade na amostra de BTC, na qual foi aplicado tratamento com mucilagem xique-xique, na dosagem mais concentrada (TX1:1) resultou em comportamento mais próximo ao obtido pelas amostras com a resina comercial acrílica impermeabilizante (TR). A desejada proteção superficial do BTC, em relação ao contato com a água, tendo como parâmetro a comparação com a resina comercial, confirmou-se, colocando em destaque o potencial da mucilagem de xique-xique como alternativa para o sistema de proteção superficial da parede de BTC.

O bom desempenho desse material natural como um produto de proteção superficial também foi demonstrado frente ao envelhecimento acelerado provocado pela ação do calor e choque térmico. A amostra TX1:1 obteve desempenho similar à amostra TR, e superior à amostra TC.

O trabalho desenvolvido iniciou o estudo para uso do produto descartado (cascas) de outras pesquisas relativas ao aproveitamento do cacto xique-xique para a indústria de beneficiamento para fins alimentícios. Demonstrou a possibilidade de produzir a mucilagem com esse material e, por meio de resultados de ensaios, comprovou sua eficiência como produto para tratamento superficial de BTC, o que qualifica seu uso para proteger da ação de água e aumentar a durabilidade de paredes executadas com terra. Por outro lado, o estudo para o uso de um material de origem natural e disponível no local está em sintonia com as exigências da sustentabilidade da construção civil, assim como o resgate inovador da cultura construtiva vernácula. $\mathrm{O}$ trabalho, entretanto, não se encerra; é preciso prosseguir a pesquisa notadamente com o estudo de diferentes dosagens e procedimentos para obtenção da mucilagem, e formas de aplicação do tratamento superficial, além da necessidade de se obter um produto de fácil preparo e aplicação que possa ser difundido para os mais diversos usuários.

\section{Referências}

ARANDA-JIMÉNEZ, Y. G.; GARCÍA-IZAGUIRRE, V. M. Efectos de la utilización de savias vegetales en los bloques de tierra comprimida con respecto a la prueba de abrasión. Legado de Arquitectura y Diseño, v. 1, n. 19, 2016.

ASSOCIAÇÃO BRASILEIRA DE NORMAS TÉCNICAS. NBR 15575-4: edificações habitacionais: desempenho: parte 4: requisitos para os sistemas de vedações verticais internas e externas - SVVIE. Rio de Janeiro, 2013.

ASSOCIAÇÃO BRASILEIRA DE NORMAS TÉCNICAS. NBR 6459: determinação do limite de liquidez. Rio de Janeiro, 2016. Versão corrigida 2017.

ASSOCIAÇÃO BRASILEIRA DE NORMAS TÉCNICAS. NBR 6459: solo: determinação do limite de liquidez. Rio de Janeiro, 1984a. 
ASSOCIAÇÃO BRASILEIRA DE NORMAS TÉCNICAS. NBR 7180: determinação do limite de plasticidade. Rio de Janeiro, 2016.

ASSOCIAÇÃO BRASILEIRA DE NORMAS TÉCNICAS. NBR 7180: solo: determinação do limite de plasticidade. Rio de Janeiro, 1984b.

ASSOCIAÇÃO BRASILEIRA DE NORMAS TÉCNICAS. NBR 7181: solo-análise granulométrica. Rio de Janeiro, 2016. Versão corrigida 2, 2018.

ASSOCIATION OF OFFICIAL ANALYTICAL CHEMISTS. Official methods of analysis. $19^{\text {th }}$. ed. Washington D.C., 2012.

AZEVEDO, J. M. C. B. Absorção por capilaridade de soluções aquosas salinas em materiais porosos. Porto, 2013. Dissertação (Mestrado em Engenharia Civil) - Universidade do Porto, Porto, 2013.

BEZERRIL, F. F. Caracterização nutricional do xique-xique (Pilosocereus gounellei (A. Weber ex. K. Wchum.) Bly. ex Rowl.) e sua utilização no processamento de geleia. João Pessoa, 2017. 66 f. Dissertação (Mestrado em Ciência e Tecnologia de Alimentos) - Universidade Federal da Paraíba, João Pessoa, 2017.

CAGNON, H. et al. Hygrothermal properties of earth bricks. Energy and Buildings, v. 80, p. 208-217, 2014.

CHIAPPERO R. O.; SUPISICHE M. C. Arquitectura de tierra: breves consideraciones sobre la conservación y restauración. Buenos Aires: Nobuko, 2006.

COLONETTI, V. C. Caracterização da mucilagem do fruto e cladódio de Cereus hildmaniannus K. Schum. Florianópolis, 2012. 82 f. Dissertação (Mestrado Engenharia Química) - Universidade Federal de Santa Catarina, Florianópolis, 2012.

CONTRERAS-PADILLA, M. et al. Physicochemical and rheological characterization of Opuntia ficus mucilage at three different maturity stages of cladode. European Polymer Journal, v. 78, p. 226-234, 2016.

DOVE, C. A.; BRADLEY, F. F.; PATWARDHAN, S. V. Seaweed biopolymers as additives for unfired clay bricks. Materials and Structures/Materiaux et Constructions, v. 49, n. 11, p. 4463-4482, 2016.

DUBOIS, M. et al. Colorimetric method for determination of sugars and related substances. Analytical Chemistry, v. 28, n. 3, p. 350-356, 1956.

EIRES, R. M. G. Construção em terra: desempenho melhorado com incorporação de biopolímeros. Minho, Tese (Doutorado em Engenharia Civil) - Escola de Engenharia, Universidade do Minho, Minho, 2012.

EIRES, R.; CAMÕES, A.; JALALI, S. Ancient materials and techniques to improve the earthen building durability. Key Engineering Materials, v. 634, p. 357-366, 2015.

EIRES, R.; CAMÕES, A.; JALALI, S. Materiais e técnicas antigas para melhorar a durabilidade dos edifícios em terra. In: CONGRESSO LUSO-BRASILEIRO DE MATERIAIS DE CONSTRUÇÃO SUSTENTÁVEIS, Guimarães, 2014. Anais [...] Guimarães, 2014.

ESPINO-DÍAZ, M. et al. Development and characterization of edible films based on mucilage of Opuntia ficus-indica (L.). Journal of Food Science, v. 75, n. 6, p. 347-352, 2010.

FABBRI, A. et al. Analysis of the water absorption test to assess the intrinsic permeability of earthen materials. Construction and Building Materials, v. 199, p. 154-162, 2019.

GREENSPAN, L. humidity fixed points of binary saturated aqueous solutions. Journal of Reserach of the National Bureau of Standards - A. Physics and Chemistry, v. 81, n. 1, 1977.

GUERRERO, R. E. L. Escolhas sustentáveis em sistemas de vedação: construção de uma métrica de avaliação relativa. João Pessoa, 2016. Dissertação (Mestrado em Arquitetura e Urbanismo) - Universidade Federal da Paraíba, João Pessoa, 2016.

HEATHCOTE, K. A. Durability of earthwall buildings. Construction and Building Materials, v. 9, n. 3, p. 185-189, 1995.

INGLESE, P. et al. Crop ecology, cultivation and uses of cactus pear. Rome: FAO, 2017.

LABOREL-PRÉNERON, A. et al. Plant aggregates and fibers in earth construction materials: a review.

Construction and Building Materials, v. 111, p. 719-734, 2016. 
LEÓN-MARTÍNEZ, F. M.; MÉNDEZ-LAGUNAS, L. L.; RODRÍGUEZ-RAMÍREZ, J. Spray drying of nopal mucilage (Opuntia ficus-indica): effects on powder properties and characterization. Carbohydrate Polymers, v. 81, n. 4, p. 864-870, 2010.

MAGALHÃES, A. C. T. V. de; ALMEIDA, J. G. de. O uso da mucilagem de cacto em pastas de gesso: efeitos na absorção de água e na resistência à flexão estática. Ambiente Construído, Porto Alegre, v. 10, n. 1, p. 139-151, jan./mar. 2010.

MAIA, L. R. Contribuição às construções em terra comprimida e influência no conforto. São Paulo, 2016. Dissertação (Mestrado em Arquitetura e Urbanismo) - Faculdade de Arquitetura e Urbanismo, Universidade de São Paulo, São Paulo, 2016.

MINKE, G. Manual de construccion en tierra: la tierra como material de construcción y su aplicación en la arquitectura actual. 2. ed. Montevideo: Fin de Siglo, 2005.

MONTEIRO, E. R. et al. Genetic diversity and structure of populations in Pilosocereus gounellei (F.A.C.Weber ex K.Schum.) (Cactaceae) in the Caatinga biome as revealed by heterologous microsatellite primers. Biochemical Systematics and Ecology, v. 58, p. 7-12, 2015.

MOREL, J.; CHAREF, R. What are the barriers affecting the use of earth as a modern construction material in the context of circular economy? IOP Conference Series: Earth and Environmental Science, v. 225, p. $1-6,2019$.

MURMU, A. L.; PATEL, A. Towards sustainable bricks production: an overview. Construction and Building Materials, v. 165, p. 112-125, 2018.

NAKAMATSU, J. et al. Eco-friendly modification of earthen construction with carrageenan: Water durability and mechanical assessment. Construction and Building Materials, v. 139, p. 193-202, 2017.

NIROUMAND, H.; ZAIN, M. F. M.; JAMIL, M. A guideline for assessing of critical parameters on Earth architecture and Earth buildings as a sustainable architecture in various countries. Renewable and Sustainable Energy Reviews, v. 28, p. 130-165, 2013.

PORTER, H. et al. Rammed earth blocks with improved multifunctional performance. Cement and Concrete Composites, v. 92, n. April, p. 36-46, 2018.

RILEM. Water absorption coefficient (capillarity). Materiaux et Constructions, v. 13, n. 75, 1980. Essai ${ }^{\circ}$ II.6.

RODRÍGUEZ-GONZÁLEZ, S. et al. Extraction and characterization of mucilage from wild species of opuntia. Journal of Food Process Engineering, v. 37, n. 3, p. 285-292, 2014.

SÁENZ, C. et al. Opuntias as a natural resource. In: FOOD AND AGRICULTURE ORGANIZATION OF THE UNITED NATIONS. Agro-industrial utilization of cactus pear. Rome: FAO, 2013.

SÁENZ, C.; SEPÚLVEDA, E.; MATSUHIRO, B. Opuntia spp. mucilage's: a functional component with industrial perspectives. Journal of Arid Environments, v. 57, n. 3, p. 275-290, 2004.

SEPÚLVEDA, E. et al. Extraction and characterization of mucilage in Opuntia spp. Journal of Arid Environments, v. 68, n. 4, p. 534-545, 2007.

SORIA, P. T. et al. La baba y el mucílago de nopal, una alternativa natural para la conservación de acabados arquitectónicos de tierra. Antropología. Boletín Oficial del Instituto Nacional de Antropología e Historia, v. 99, 2015.

TATANE, M. et al. Effect of argan nut shell powder on thermal and mechanical behavior of compressed earth blocks. International Journal of Applied Engineering Research, v. 13, n. 7, p. 4740-4750, 2018.

UDAWATTHA, C. et al. Performance of natural polymers for stabilizing earth blocks. Materialia, v. 2 , n. July, p. 23-32, 2018.

VARES, O. et al. Determination of hygrothermal performance of clay-sand plaster: Influence of covering on sorption and water vapour permeability. Energy Procedia, v. 132, p. 267-272, 2017.

VARGAS-RODRÍGUEZ, L. et al. Physical properties of mucilage prickly pear. Acta Universitaria, v. 26, n. NE-1, p. 8-11, 2016. 
Ana Beatriz Egypto Queiroga da Nóbrega

Programa de Pós-Graduação em Engenharia Civil e Ambiental | Universidade Federal da Paraíba | Via Expressa Padre Zé, s/n, Centro de Tecnologia, Campus I, Castelo Branco | João Pessoa - PB - Brasil | Tel.: (83) 98846-8386 | E-mail: anabqnobrega@gmail.com

\section{Aluísio Braz de Melo}

Departamento de Arquitetura e Urbanismo | Universidade Federal da Paraíba | Tel.: (83) 3216-7115 | E-mail: aluisiobmelo@hotmail.com

\section{Ambiente Construído}

Revista da Associação Nacional de Tecnologia do Ambiente Construído

Av. Osvaldo Aranha, $99-3^{\circ}$ andar, Centro

Porto Alegre - RS - Brasil

$$
\text { CEP } 90035-190
$$

Telefone: +55 (51) 3308-4084

www.seer.ufrgs.br/ambienteconstruido

www.scielo.br/ac

E-mail: ambienteconstruido@ufrgs.br

(c) (i) This is an open-access article distributed under the terms of the Creative Commons Attribution License.

176 Nóbrega, A. B. E. Q. da; Melo, A. B. de. 